\title{
Granulomatous interstitial lung disease in a long-term drug abuser
}

\author{
Karen Laudenbach*, Jan Koch, Bernd Seese \\ Thoraxzentrum Bezirk Unterfranken, Münnerstadt, Germany; *Corresponding Author: K.Laudenbach@tzbu.de
}

Received 3 March 2010; revised 14 April 2010; accepted 15 April, 2010.

\begin{abstract}
It is the habit of some drug consumers to dissolve the powder of crushed pills, intended for oral use, in water and inject this solution intravenously. Insoluble particles than obstruct pulmonary vessels causing microscopic pulmonary emboli. These foreign bodies migrate and penetrate into the perivascular space and interstitium, resulting in chronic inflammation and foreign body giant cell reaction. As a result of this a granulomatous interstitial fibrosis can develop, which has also been described as pulmonary talcosis. We are reporting the case of a 22 year old male with a history of long-term intravenous drug abuse. He presented to our hospital complaining of dyspnoea, cough and generalized weakness. We describe an extensive diagnostic process concluded by an open lung biopsy establishing a definitive diagnosis of this rare granulomatous lung disease. This case underlines the importance of a thorough diagnostic work up and the pathogenic potential of foreign material reaching the lung via blood circulation in amongst the differential diagnoses of interstitial lung diseases, especially occurring in this group of patients.
\end{abstract}

Keywords: Pulmonary Talcosis; Granulomatous Pneumoconiosis; Drug Abuse; Heroin; Foreign Body Granuloma; Interstitial Lung Disease

\section{CASE REPORT}

We report of a 22 year old male Patient with a history of intravenous heroine use since he was 15 years old. His general health had been deteriorating for some months. At presentation he complained of increasing shortness of breath on exertion, fatigue and fainting episodes.

\section{PHYSICAL EXAMINATION}

The patient seemed malnourished and overall in poor health. On auscultation he had normal breath sounds. A systolic murmur over the tricuspid valve area was noted.

Examination of the abdomen, musculoskeletal system and nervous system was without pathological findings.

\section{DIAGNOSTIC RESULTS}

Chest Radiograph: Showed diffuse interstitial pulmonary nodules.

Blood results: ACE $57 \mathrm{U} / \mathrm{l}(<52)$, CRP $10.2 \mathrm{mg} / \mathrm{dl}$, specific IgG against mould and candida-negative, DDimer $1.3 \mathrm{mg} / \mathrm{l}(<0.3)$, BNP 1433pg/ml Serology for Legionella and Mycoplasma-negative Anti-HCV-positive, HIV I and II-negative.

Arterial Blood Gases (ABG): pH: $7.48 \mathrm{pCO}_{2} 28 \mathrm{mmHg}$, $\mathrm{pO}_{2} 87 \mathrm{mmHg}$, Bicarbonate $22.8 \mathrm{mval} / \mathrm{l}$. BE -1, 9 .

Pulmonary Function Test: (Bodyplethysmography) Forced expiratory volume (FEV1) 2.2l (53\% predicted), vital capacity (VC) 2.82l (56\%), FEV1/VC 78\% (94\%), Total lung capacity (TLC) 4.67l (74\%), Gas transfer (TLCO) $5.24 \mathrm{mmol} / \mathrm{min} / \mathrm{kPas}$ (47\%).

Echocardiography: Tricuspid regurgitation (Grade 3), systolic pulmonary artery pressure (PAPsyst.) $37 \mathrm{mmHg}$ + central venous pressure.

Electrocardiography: Sinusrhythm, Right bundle branch block

High-resolution-CT Thorax: diffuse interstitial and fine micronodular infiltration in throughout both lungs (Figure 1).

Bronchoscopy: no abnormal findings. Bronchial aspirate: scanty E.coli and Staphylococcus aureus. No acid fast bacilli.

Bronchoalveolar lavage: some smoker macrophages, otherwise unremarkable

Transbronchial biopsy: Evidence of extensive granulomatous interstitial fibrosis.

Under polarized light: granulomas containing crystal- 
line birefringent material (Figure 2).

The patients overall condition improved with symptomatic treatments. Over the following month he did however continue to inject heroin. He also admitted to inject a mixture of cigarette ashes and water into his femoral vein on at least one occasion.

Six months later he was re-hospitalized due to right sided chest pain, combined with acute dyspnoea, general weakness and cough with brownish expectoration. He was hypotensive (blood pressure $70 / 40 \mathrm{mmHg}$ ) with a heart rate of $120 \mathrm{bpm}$.

\section{FINDINGS}

Blood results: CRP 8.6 mg/dl, D-Dimer 3.6 mg/l, E.coli on sputum examination

Pulmonary function test (Bodyplethysmography): FEV1 1.041 (25\% predicted), FEV1/VC 69\% (83\%), VC 1.491 (30\%), TLC 4.37l (69\%).

ABG: pH 7.48 pCO $_{2} 23.7$ mmHg pO $54.4 \mathrm{mmHg}$

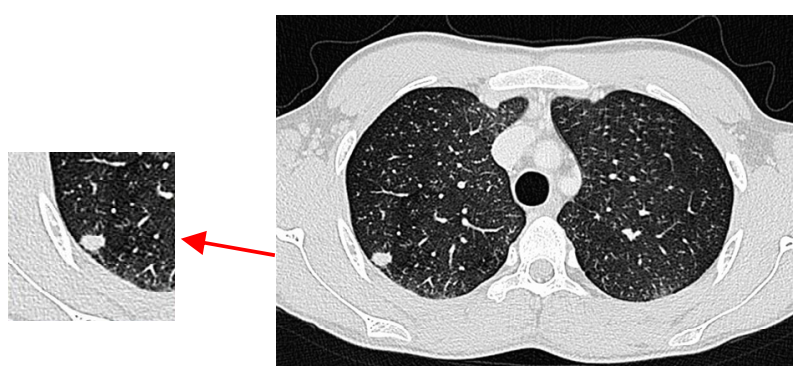

Figure 1. High resolution CT Thorax: diffuse interstitial micronodular pattern with conglomerate formation.

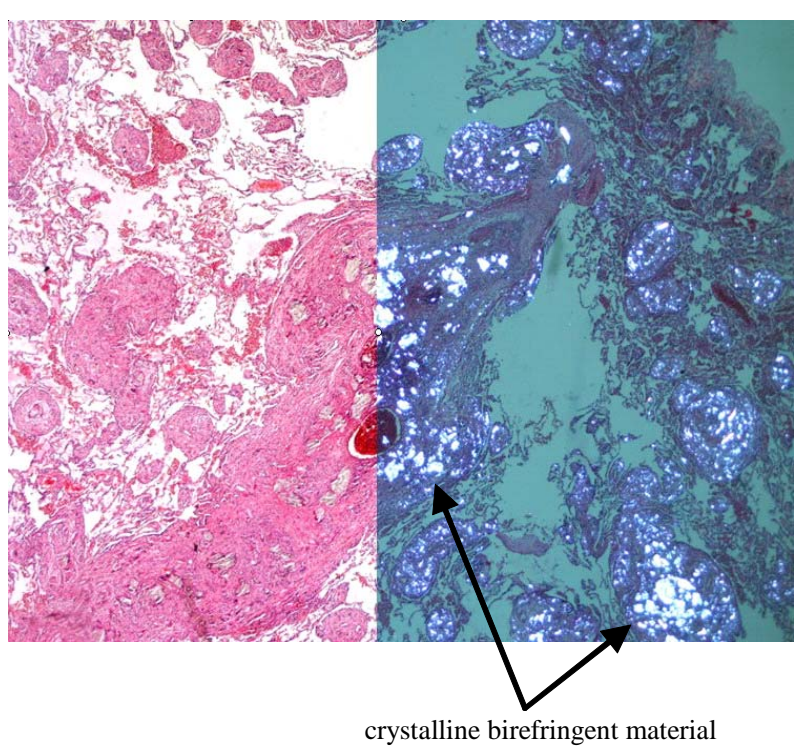

Figure 2. left: H\&E-stain, right: under polarized light, positive birefringent material $(2.5 \times$ magnified $)$.
Bicarbonate $17.5 \mathrm{mmol} / \mathrm{l}, \mathrm{BE}-4,4$.

High resolution CT Thorax: progressive diffuse interstitial, micronodular changes throughout both lungs. Bilateral small single nodules, one in the right lower lobe measuring $13 \mathrm{~mm}$, one right paracardial measuring $10 \mathrm{~mm}$.

Ventilation/Perfusion scintigraphy 12 days after hospitalization: no evidence of new or old pulmonary emboli.

Doppler ultrasound of the legs: no pathological findings.

Under symptomatic treatment including antibiotics according to sensitivities and oxygen-therapy his condition and cardiopulmonary status stabilized within a few days. Blood gas analysis returned to normal. A short course of systemic Corticosteroids (Prednisolon at a dose of $0.5 \mathrm{mg} / \mathrm{kg}$ bodyweight) was given.

In order to establish a definitive diagnosis the patient underwent an open lung biopsy a month later. Tissue sample were obtained from the right lower lobe (S6/9) and the right upper lobe.

Macroscopically the lung had a fine granular appearance. The cut surface presented small up to $4 \mathrm{~mm}$ sized brown nodules and a tumourous conglomerate in the specimen from left lower lobe.

Histologically there was strong granulomatous inflammation caused by foreign material with surrounding interstitial fibrosis. The appearances were in keeping with a pulmonary talcosis (drug abuser lung). The specimen from the upper lobe showed a patchy pneumonia with multiple foci of abscess formation.

\section{DISCUSSION}

Chest radiography and high resolution CT showed a diffuse interstitial lung disease. The pulmonary function test demonstrated moderately severe restrictive and obstructive airflow and a reduction in diffusion capacity.

Patchy pneumonic changes seen in the histological specimen were felt to be of a secondary nature. A primary bacterial or tuberculous origin of the manifest interstitial changes could be excluded. There was nothing in the patient's history to suggest extrinsic allergic alveolitis. Serology for that purpose was also negative.

Transbronchial biopsy as well as open lung biopsy demonstrated histological evidence of granulomatous inflamemation surrounding typical foreign body giant cells. In the centre of these granulomas parts of blood vessels and capillaries could be seen suggesting that foreign material reached the lung via venous circulation. (Figure 4) This histological finding is typical for an intravenous pulmonary talcosis (drug abuser lung).

Drug users often inject the powder of crushed pills, 
intended for oral use, dissolved in water. These often contain a particular filler such as talc, starch or cellulose, magnesium stearate and silica [1,2]. Insoluble particles obstruct pulmonary arteries and capillaries causing microscopic pulmonary emboli. In the following stage these foreign bodies migrate and penetrate into the perivascular space and interstitium where they cause chronic inflammation and provoke a foreign body giant cell reaction [3]. The result is a granulomatous interstitial fibrosis (drug abuser lung). The physician is confronted with a broad clinical spectrum ranging from no symptoms up to fulminant disease and death. Common symptoms are cough, progressive dyspnoea and weight loss [4].

Auscultation may be unremarkable or reveal discrete bibasal crackles.

Sometimes patients present with mild or moderate hypoxia. Pulmonary function tests can be restrictive or obstructive. A typical diagnostic finding is an impairment of gas transfer [5].

Chest x-ray may be normal, but might show compact diffuse masses [6]. Transbronchial biopsy or surgical lung biopsy will confirm the diagnosis of pulmonary talcosis. The characteristic histological finding would be a granulomatous inflammatory reaction, with foreign material enclosed in typical foreign body giant cells (Figure 3).

Following long term drug abuse there are a range of patterns in which talcosis can be seen on CT. They consist of fine micronodular pattern, conglomerate parahilar masses on a background of micronodularity, ground glass attenuation, and panacinar or centrilobular emphysema. These patterns frequently appear in combination [7].

Other manifestations include pneumothorax, pulmonary hypertension, pulmonary fibrosis and chronic respiratory failure in the final stage [3]. Up to $80 \%$ of long term drug abusers can develop a talc retinopathy. Over $23 \%$ of intravenous drug addicts show evidence of septic emboli [8].

Silicosis and sarcoidosis are the two most important differential diagnoses to be considered. Due to the possibility of a coexisting HIV infection miliary tuberculosis should also be thought of and excluded by bronchial lavage.

Miliary metastases and opportunistic respiratory infections such as Pneumocystis jirovecii, CMV or atypical pneumonia (Legionella and Chlamydia) are further important differential diagnoses. An extrinsic allergic alveolitis should be excluded by serology and history taking.

Reports on the natural course and treatment of talc granulomatosis are scarce. Pare et al. described irreversible progression of radiographic abnormalities, even after long term abstinence [3]. The most important therapeutic

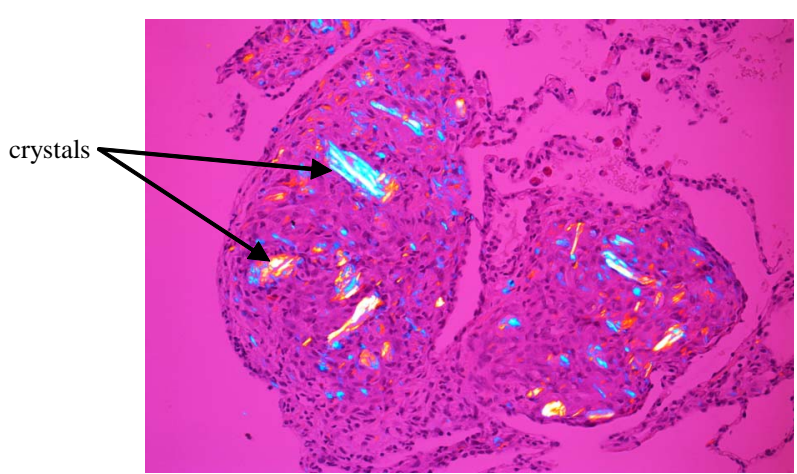

Figure 3. Foreign body granuloma with crystals $(10 \times$ magnified).

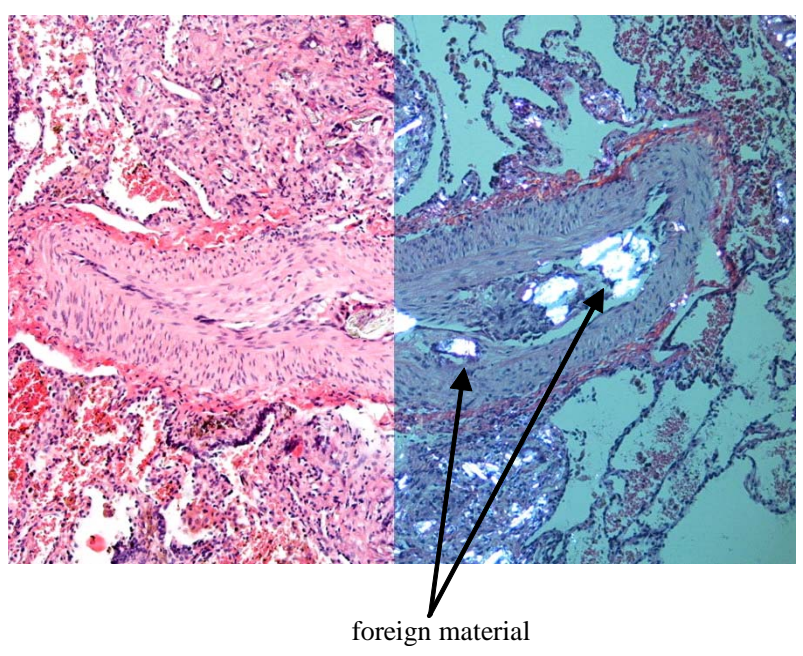

Figure 4. Pulmonary vessel with intraluminal foreign material.

intervention however is to stop any further intravenous drug use, smoking cessation and adequate treatment of significant pulmonary hypertension.

Smith et al. describe a positive response to treatment with corticosteroids, initially at a dose of $60 \mathrm{mg}$ Prednisolone daily [4]. In some severe cases of talcosis lung transplantation could be considered, providing complete drug abstinence can be confirmed [9].

\section{CONCLUSIONS}

Interstitial lung disease needs thorough and often extensive diagnostic clarification.

Whilst inhaled environmental and industrial agents represent an important factor in the pathogenesis of this disease group, we must also consider substances and foreign material reaching the lung via blood circulation and other pathways as described in this case.

It illustrates very well the importance of completing the diagnostic process, reminding the physician of this 
rare cause of granulomatous lung disease in a specific high risk population.

\section{ACKNOWLEDGEMENTS}

There is no conflict of interest. The corresponding author confirms, there is no liability to any of the firms mentioned in this article. The presentation is independent and the content remains neutral.

\section{REFERENCES}

[1] Kringsholm, B. and Christoffersen, P. (1987) The nature and the occurrence of birefringent material indifferent organs in fatal drug addiction. Forensic Science International, 34(1-2), 39-45.

[2] Fraser, R.G., Pare, J.A.P., Pare, P.D., Fraser, R.S. and Genereux, G.P. (1990) Embolic and thrombotic diseases of the lungs in Diagnosis of diseases of the chest. 3rd Edition, Saunders Company, Philadelphia, 1794-1803.

[3] Pare, J.P., Cote, G. and Fraser, R.S. (1989) Long-term follow up of drug abusers with intravenous talcosis.
American Review of Respiratory Disease, 139(1), 233-241.

[4] Smith, R.H., Graf, M.S. and Silvermann, J.F. (1978) Successful management of drug-induced talc granulomatosis with corticosteroids. Chest, 73(4), 552-554.

[5] Conen, D., Schilter, D., Bubendorf, L., Brutsche, M.H. and Leuppi, J.D. (2003) Interstitial lung disease in an intravenous drug user. Respiration, 70(1), 101-103.

[6] Douglas, F.G., Kafilmout, K.J. and Patt, N.L. (1971) Foreign particle embolism in drug addicts: Respiratory pathophyiology. Annals of Internal Medicine, 75(6), 865-880.

[7] Ward, S., Heynemann, L.E., Reittner, P., Kazerooni, E.A., Godwin, J.D. and Müller, N.L. (2000) Talcosis associated with iv abuse of oral medications: CT findings. American Journal of Roentgenology, 174(3), 789-793.

[8] O’Donnell, A.E. and Pappas, L.S. (1988) Pulmonary complications of intravenous drug abuse. Experience at an innercity hospital. Chest, 94(2), 251-253.

[9] Cook, R.C., Fradet, G., English, J.C., et al. (1998) Recurrence of intravenous talc granulomatosis following single lung transplantation. Canadian Respiratory Journal, 5(6), 511-514. 